\title{
FORMATION OF RECTANGULAR CHANNELS IN FUSED SILICA BY LASER-INDUCED CHEMICAL ETCHING
}

\author{
V. Stankevič and G. Račiukaitis \\ Center for Physical Sciences and Technology, Savanoriu 231, LT-02300 Vilnius, Lithuania \\ E-mail: valdemar.s@e-lasers.com
}

Received 17 April 2014; accepted 29 May 2014

\begin{abstract}
In this paper, we report results of our research on the formation of micro-channels with the rectangular cross section inside bulk fused silica. The selective etching of channels was performed by the technique called the femtosecond laser induced chemical etching. Hydrofluoric acid was used as an agent for selective removal of laser-modified regions in fused silica samples. The method of the channel cross section control based on multiple scanning is proposed. The effect of scanning speed, laser pulse energy, and polarization on the etching selectivity was investigated and discussed.
\end{abstract}

Keywords: femtosecond microfabrication, micro-channels, selective chemical etching, fused silica, internal modification

PACS: 06.60.Jn, 34.80.Qb, 42.62.Cf, 79.20.Ws

\section{Introduction}

Femtosecond laser micromachining combined with chemical etching is a flexible and well established technique for several application fields including manufacturing lab-on-chip [1], integrated optics [2] 3], embedded three-dimensional microsystems in bulk fused silica which combine optical, mechanical, and fluid transportation functions inside a single substrate [4]. Ultrashort laser pulses are required to produce local modifications of the material. Using femtosecond pulses, the light-matter interaction takes place in a timescale which is much shorter than electron-phonon relaxation time (several picoseconds). Therefore, the material modifications are confined in a focal area with diminishing thermal effect to the neighbouring areas. Fundamental processes of the femtosecond-pulse modification in bulk transparent materials are described in [5].

Morphological changes in fused silica irradiated by femtosecond pulses depend on parameters of laser radiation (wavelength, repetition rate, pulse duration, energy, etc.) as well on the material properties (bandgap, thermal conductivity, etc.). Depending on the used laser fluence and the dose, the structural modifications in transparent materials can be divided in three categories [6-8]:

- Positive/negative change of the refractive index induced with the laser fluence ( $100 \mathrm{~nJ}$ for $0.6 \mathrm{NA}$ (numerical aperture) focusing of $800 \mathrm{~nm}, 100 \mathrm{fs}$ pulses [5], fluence $\sim 4 \mathrm{~J} / \mathrm{cm}^{2}$ ) which only slightly exceeds the structural modification threshold [6] and is called type-I modification. This regime is commonly used for waveguides writing in bulk dielectrics.

- Type-II modification occurs when a higher fluence is applied ( $150-500 \mathrm{~nJ}$ for $0.6 \mathrm{NA}$ focusing of $800 \mathrm{~nm}, 100 \mathrm{fs}$ pulses [5], fluence $\sim 6-20 \mathrm{~J} / \mathrm{cm}^{2}$ ) and nano-gratings with a sub-wavelength period appear 㧅. This phenomenon has been observed only in fused silica. Orientation of nanostructures is perpendicular to the linear laser polarization. This irradiation regime is used in the femtosecond laser induced chemical etching (FLICE) technique and enhances the rate of the selective chemical etching [9].

- At the fluence (>500 nJ for $0.6 \mathrm{NA}$ focusing of $800 \mathrm{~nm}, 100 \mathrm{fs}$ pulses [5], fluence $>20 \mathrm{~J} / \mathrm{cm}^{2}$ ) which induces destructive modification in the material (type-III modification) voids and microexplosions appear [10, 11]. This regime cannot be used for chemical etching and was not considered further in our research.

The femtosecond laser modification of transparent materials combined with chemical etching was first reported by Marcinkevičius et al. [12] in fused silica. This process involved two steps: 
1) Exposure with a femtosecond laser. Local modification zones were formed in a fused silica sample with the low-energy laser pulses by using the direct laser writing technique.

2) Chemical etching. The fused silica substrate was immersed in a diluted hydrofluoric (HF) acid (2.5-20\% of concentration). The material regions which were modified with the laser radiation were etched significantly faster. A typical ratio of the etching rates of the modified and non-modified regions was 60:1 [13].

Depending on optical properties of the material and by tailoring the suitable laser processing parameters, different kinds of modifications can be produced as described above. We limited the used laser fluence to the type-II modification in fused silica in order to facilitate the nano-gratings formation [14]. The proper window of laser processing parameters was selected by the probe test, varying laser irradiation and estimating the etching selectivity. In this paper, micro-channels of the rectangular cross section inscribed with the FLICE technique are demonstrated. We show the possibility of micro-channel writing with a high scanning speed when different laser parameters (290 fs, $515 \mathrm{~nm}$, NA 0.55) compared to those reported by Hnatovsky et al. ( $40 \mathrm{fs}, 800 \mathrm{~nm}$, NA 0.65) [14] are used. Due to the increase of the laser repetition rate from $100 \mathrm{kHz}$ [9, 14] up to $500 \mathrm{kHz}$, the processing speed can be accelerated up to $1 \mathrm{~mm} / \mathrm{s}$ by preserving the irradiation dose similar to that described in [14]. The fast writing speed reduces the overall production time of the microstructures. The effect of scanning speed, laser pulse energy, and polarization direction on the etching selectivity and shape of the channels was investigated and discussed.

\section{Experimental set-up}

Rectangular samples $\left(15 \times 10 \times 2 \mathrm{~mm}^{3}\right)$ of optically polished ultraviolet grade fused silica (JGS1) were irradiated with ultrashort laser pulses with the pulse duration of $290 \mathrm{fs}$ at the repetition rate of $100-500 \mathrm{kHz}$ delivered from the diode-pumped mode-locked Yb:KGW laser Pharos (Light Conversion, Ltd.) working at second harmonics $(\lambda=515 \mathrm{~nm})$. The experiments were performed on the laser processing system consisting of a fs laser, beam delivery optics, sample positioning $X Y$ stages, and control software. The system was assembled by ELAS Ltd. The experimental set-up is shown in Fig. 1 .

The second harmonics beam from the laser was attenuated with a motorized Brewster angle attenuator and delivered to the $50 \times$ microscope objective
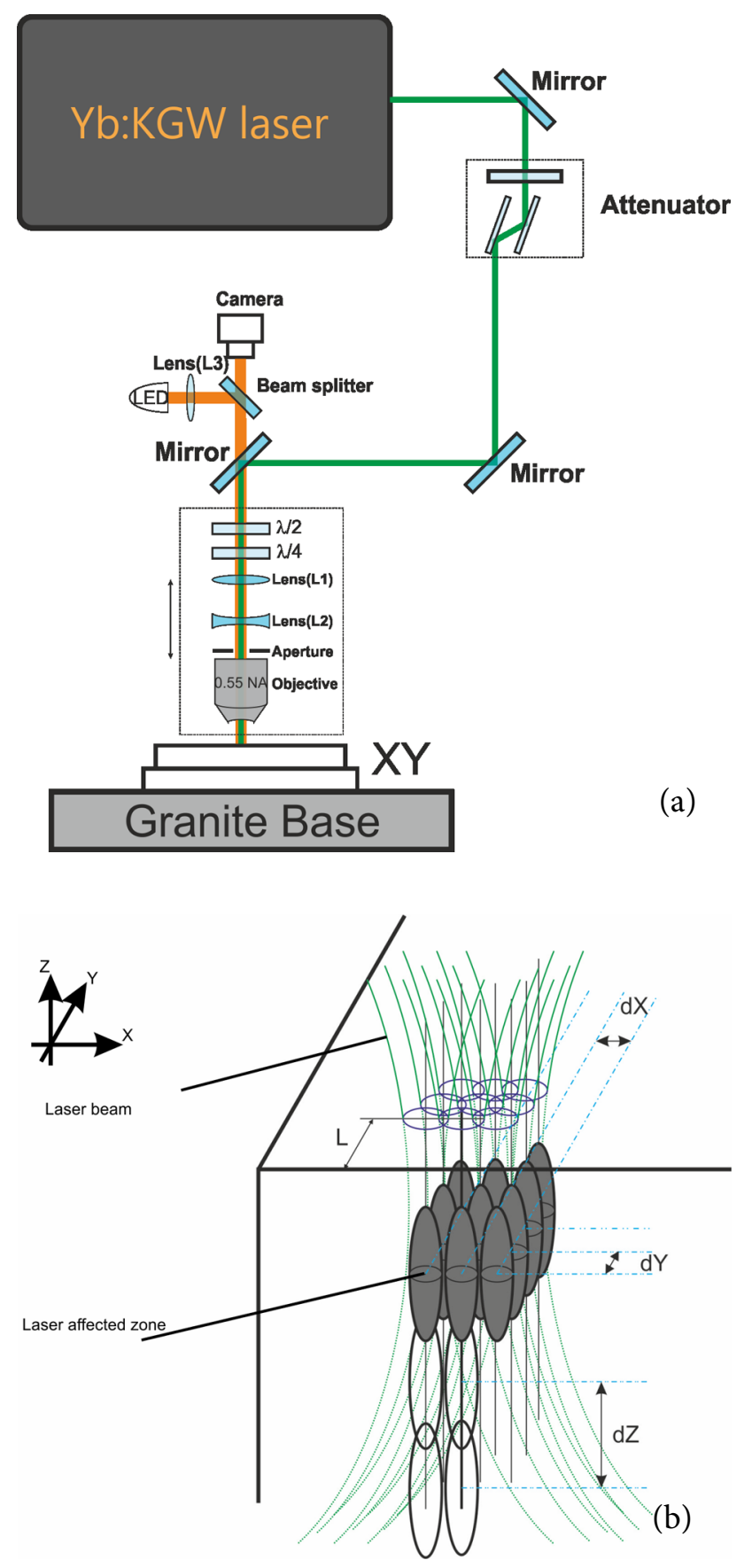

Fig. 1. Schematic diagram of (a) experimental set-up for structural modifications in bulk fused silica: L1 is the plano-convex lens (focal length $f=100 \mathrm{~mm}$ ), L2 is the plano-concave lens $(f=-50 \mathrm{~mm}), \mathrm{L} 3$ is the achromatic lens $(f=200 \mathrm{~mm})$, and (b) principle of rectangular channel formation by writing the line arrays in a bulk fused silica similar to [13].

(Olympus LMPlan, NA 0.55) which focused the laser radiation inside the bulk fused silica sample. Lenses $\mathrm{L} 1$ and L2 were used to reduce the laser beam diameter to fit into the objective aperture. Linear or circular polarization of the laser beam was controlled during 
the experiments by a set-up formed with the zero-or$\operatorname{der} \lambda / 2$ or $\lambda / 4$ phase plates mounted in the mechanical rotation holders.

The Glan prism polarizer was used to set the correct polarization orientation. The fused silica substrate was moved in $x$ and $y$ directions under the laser beam using positioning stages ANT130 (Aerotech) with the nanometre resolution. The laser writing was performed at the scanning speed varying from 0.1 to $10 \mathrm{~mm} / \mathrm{s}$ in directions ( $x$ or $y$ ) perpendicular to the laser beam propagation $(z)$. In order to control the accurate sample positioning, the off-axis machine vision system with a coaxial lighting and a charge coupled device (CCD) camera was installed. Lens L3 was used for image formation on the CCD camera matrix.

\section{Results and discussions}

\subsection{Influence of polarization direction on etching selectivity}

The single-line micro-channels were inscribed $\sim 220 \mu \mathrm{m}$ under the sample surface using the laser pulse energy in the range of 264-466 $\mathrm{nJ}$ (fluence $7.6-13.4 \mathrm{~J} / \mathrm{cm}^{2}$ ) and the writing speed in the range of $0.1-1 \mathrm{~mm} / \mathrm{s}$ at the $500 \mathrm{kHz}$ pulse repetition rate. Polarization of the incident laser radiation was controlled by rotation of the phase plate. The physical angle of the $\lambda / 2$-phase plate was rotated by $45^{\circ}$ with $5^{\circ}$ increment which corresponded to the $90^{\circ}$ rotation of the linear polarization orientation. The embedded micro-channels formed with the polarization parallel and perpendicular to the writing direction are shown in Fig. 2 .

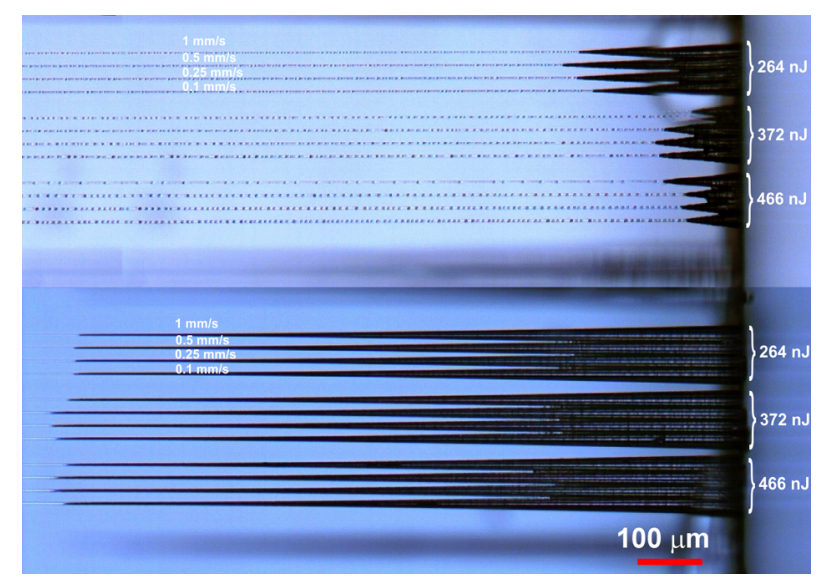

Fig. 2. The single-line micro-channels inscribed in the fused silica sample. Polarization was (top) parallel and (bottom) perpendicular to the writing direction (laser pulse energy: 264, 372, and $466 \mathrm{~nJ}$ from top to bottom between groups; writing speed: $1,0.5,0.25$, and $0.1 \mathrm{~mm} / \mathrm{s}$ from top to bottom in each group).
As could be expected from [14, the minimal etching rate was for the polarization parallel to the writing direction in Fig. 2. Due to the difference in chemical etching with parallel and perpendicular polarizations and laser fluency similar to that described in [13] we can suppose that type-II modifications were induced and conditions for nano-gratings formation were satisfied. Because the nano-grating planes induced in fused silica are formed perpendicular to the polarization orientation [14], consequently, the acid penetrates alternately the modified and non-modified material, and the later is etched slowly. When the angle between the grating planes and writing direction approached $0 \mathrm{deg}$ (Fig. 3), it facilitated penetration of the acid inside the channel and caused a better etching selectivity.

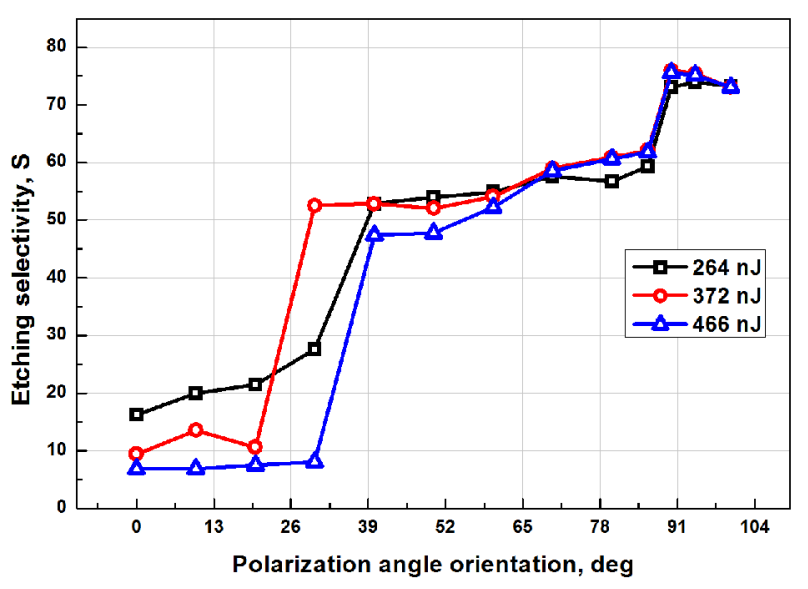

Fig. 3. Etching selectivity versus polarization orientation relative to the writing direction (writing speed $250 \mu \mathrm{m} / \mathrm{s}$, laser repetition rate $500 \mathrm{kHz}$, etching in $15 \%$ $\mathrm{HF}$ acid for $6 \mathrm{~h}$ ).

\subsection{Formation of rectangular cross section channels}

Micro-channels were formed $\sim 250 \mu \mathrm{m}$ under the sample surface by writing the multiple line arrays as shown in Fig. 1 (b). The focusing depth was controlled with the machine vision system. The micro-channels made of multiple lines were inscribed inside a fused silica sample using 4 different laser pulse energies: 200, 660, 1300, and $1700 \mathrm{~nJ}$ (appropriate fluences $5.8,19.1,37.5$, and $49 \mathrm{~J} / \mathrm{cm}^{2}$ ) at the repetition rate of $100 \mathrm{kHz}$. The channels with each energy setting were formed four times by varying the scanning speed ( 1 , $0.5,0.2$, and $0.05 \mathrm{~mm} / \mathrm{s})$. After the laser irradiation process, the modified fused silica substrates were polished and immersed into aqueous dilution of HF acid $(10 \%)$ for $6 \mathrm{~h}$ at room temperature. The samples were rinsed in 2-propanol after the etching process.

The etched micro-channels with a rectangular cross section are shown in Fig. 4. The etched channels appear 
(a)
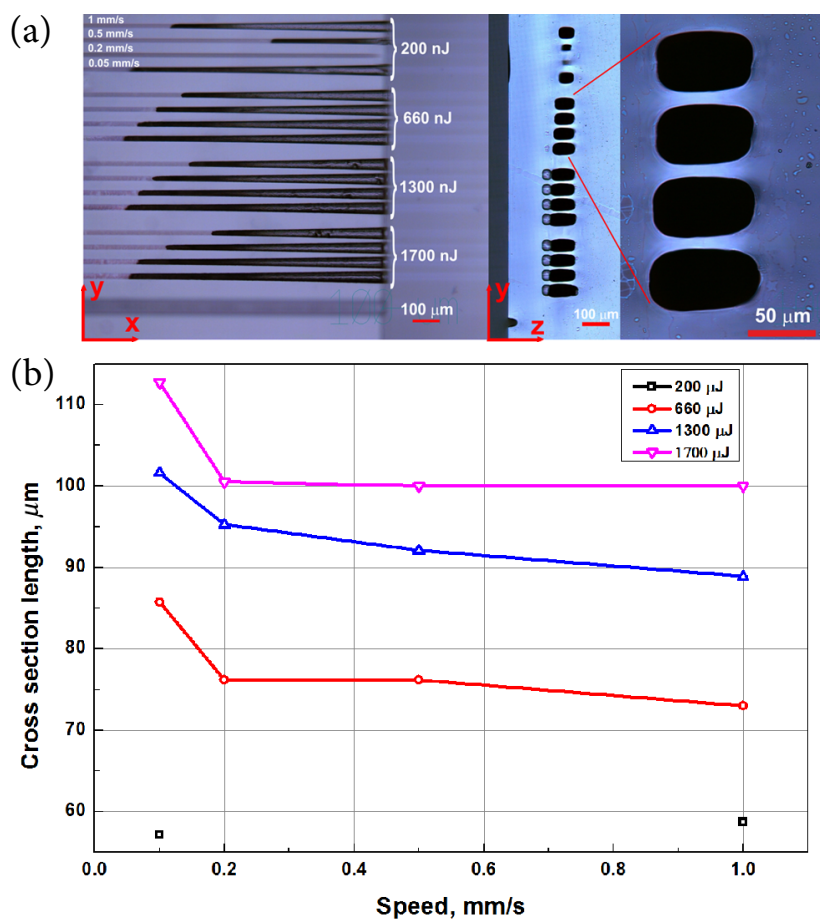

Fig. 4. Transmission-light optical microscope pictures of micro-channels etched in $10 \% \mathrm{HF}$ acid for $6 \mathrm{~h}(8 \times 3$ line array) inscribed with polarization perpendicular to the writing direction and repetition rate of $100 \mathrm{kHz}$ : (a) $x y$-view (right) and $z y$-view (left) (laser pulse energy: $200,660,1300$, and $1700 \mathrm{~nJ}$ from top to bottom between groups; writing speed: $1,0.5,0.2$, and $0.05 \mathrm{~mm} / \mathrm{s}$ from top to bottom in each group) and (b) micro-channel cross section length dependence on the scanning speed with different laser pulse energies.

black and are well distinguished with a transmissionlight optical microscope equipped with the crossed polarizers. The laser-modified but non-etched areas appear bright due to laser-induced birefringence. The multiple-line scanning in the $x$ direction with a spacing between the lines in $y(2 \mu \mathrm{m})$ and $z(3 \mu \mathrm{m})$ directions was performed (Fig. 1(b)). In such a way, the channels with a square cross section were formed by $8 \times 3$ scanning lines in $y$ and $z$ directions before the etching. The proposed method of the line-array writing can be used for inscribing channels of any desired size with a rectangular or square cross sectional shape. The size of micro-channels can be adjusted by varying the line count in $y$ and $z$ directions as well by changing the spacing between the inscribed lines.

The longitudinal voxel size depends on the applied fluence as can be seen from the $z y$-view in Fig. $4(\mathrm{a}, \mathrm{b})$. By increasing the laser pulse energy, the longitudinal modification of voxel increased faster than transversal modification, and the height-to-width ratio of a rectangular cross section increased. Therefore, the channel size in the $z$ direction can also be adjusted by varying the laser pulse energy. The scanning speed had just a slight influence to the channel cross section dimensions.

\subsection{Etching selectivity versus polarization}

The channel writing experiments were carried out using different laser beam polarizations: perpendicular and parallel to the writing $(x)$ direction and circular polarization. Even though fused silica is an isotropic material, we found that the etching rate depended on the used laser polarization. The etching selectivity can be characterized by the $S$ parameter according the following formula:

$$
S=\frac{l / h+r_{0}}{r_{0}},
$$

where $l$ is the etched channel length in $\mu \mathrm{m}, h$ is etching time in hours, $r_{0}$ is the etching rate of a non-modified fused silica in $\mu \mathrm{m} / \mathrm{h}$.

The etching rate of the non-modified fused silica was estimated by measuring the modified channel width before etching and etched channel width at entrance. The etching rate was $\sim 1.7 \mu \mathrm{m} / \mathrm{h}$ in case of using $10 \% \mathrm{HF}$ acid, and $\sim 2.4 \mu \mathrm{m} / \mathrm{h}$ for the $15 \% \mathrm{HF}$ acid etching. Dependence of the etching selectivity on the laser pulse energy for different polarizations is shown in Fig. 5 .

It was suggested that for circular polarization disordered nanostructures were formed [9]. This phenomenon allowed fast acid penetration to the modified zone, and the etching selectivity appeared similar to that of the micro-channels formed with polarization perpendicular to the writing direction.

When the laser pulse energy was increased (Fig. 5), the etching selectivity reached its maximum value. Further increase of the pulse energy led to reduction in the etching selectivity due to defect formation (type-III modification at pulse energy $>660 \mathrm{~nJ}$ ) until it reached some saturation value as shown in 15. The etching selectivity as high as 80:1 was achieved when the high laser pulse repetition rate was used $(500 \mathrm{kHz})$.

Interestingly, the selectivity versus pulse energy saturation effect was not observed when the selective etching with heated potassium hydroxide $(\mathrm{KOH})$ was investigated by Kiyama et al. [16]. By using this alternative etching agent, the channels with a higher aspect ratio can be achieved. Unfortunately, the process is more time-consuming due a smaller etching rate compared to the etching rate achieved with HF acid. The results show that the optimal laser fluence exists when the etching rate is the highest, and the processing window for various applications can be defined. 


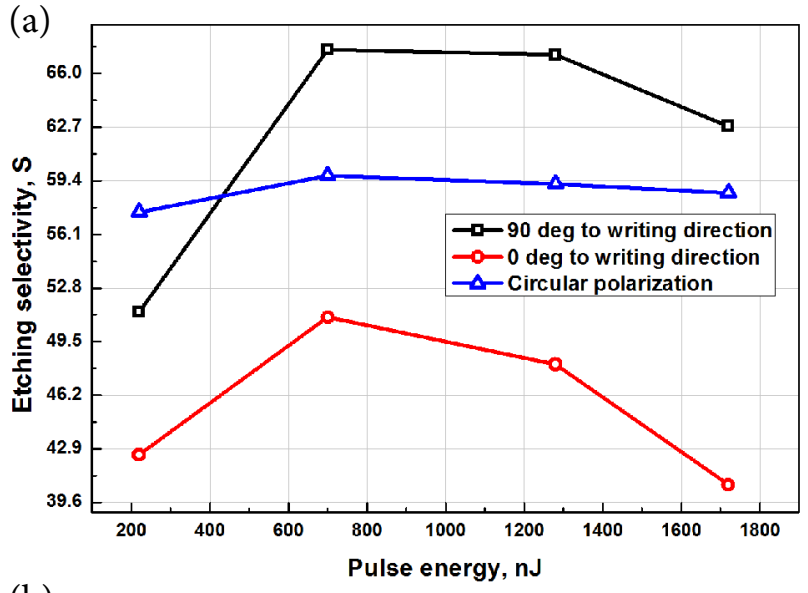

(b)

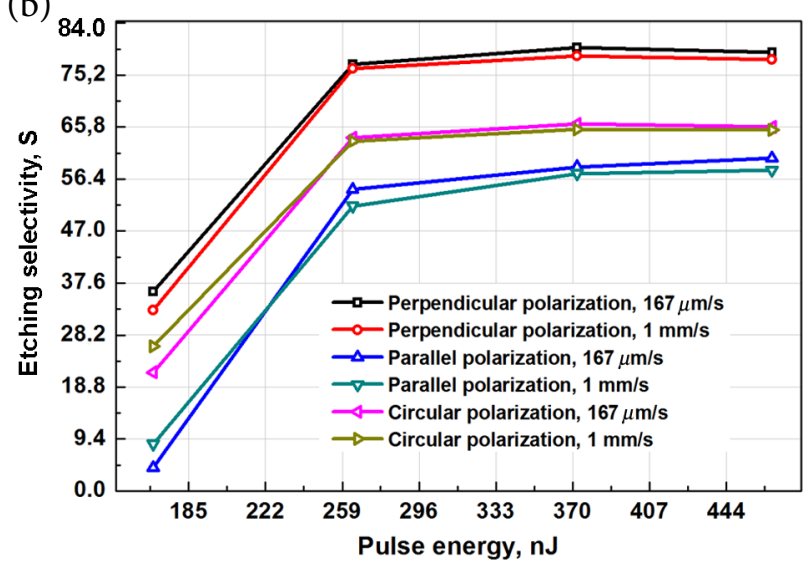

Fig. 5. Dependence of the etching selectivity on the laser pulse energy by using perpendicular, parallel, and circular polarization of laser radiation at (a) writing speed of $500 \mu \mathrm{m} / \mathrm{s}$ and laser repetition rate of $100 \mathrm{kHz}$ and (b) writing speed of $167 \mu \mathrm{m} / \mathrm{s}$ and $1 \mathrm{~mm} / \mathrm{s}$ and laser repetition rate of $500 \mathrm{kHz}$.

\section{Conclusions}

The method of inscribing micro-channels in fused silica by using the line-array writing is presented. This method can be applied for the formation of channels with the rectangular cross section of different size. The size of the rectangular cross section was controlled by adjusting laser pulse energy and dimension of the lines array. By increasing laser pulse energy, the longitudinal modification of voxel increased faster than the transversal modification, and the height-towidth ratio of the rectangular channel increased. The processing speed used in this work just slightly influenced the channel cross section dimensions. The negligible changes of the channel cross section appeared due to the laser pulse energy.

The micro-channels were inscribed in the fused silica substrate by using linear and circular polarization. The etching selectivity for the polarization per- pendicular to the writing speed was higher than that for parallel polarization but similar compared to the case of circular polarization. The experiments showed that the processing speed can be increased when the laser with a higher repetition rate is used. The processing speed up to $1 \mathrm{~mm} / \mathrm{s}$ was increased with the $500 \mathrm{kHz}$ repetition rate laser.

This work is an introduction to the formation of more complicated 3D structures in fused silica substrates for fluidic applications.

\section{References}

[1] R.W.Jr. Applegate, J. Squier, T. Vestad, J. Oakey, D.W.M. Marr, P. Bado, M.A. Dugan, and A.A. Said, Microfluidic sorting system based on optical waveguide integration and diode laser bar trapping, Lab Chip 6, 422-426 (2006).

[2] S. Nolte, M. Will, J. Burghoff, and A. Tuennermann, Femtosecond waveguide writing: a new avenue to three-dimensional integrated optics, Appl. Phys. Mater. Sci. Process. 77, 109-111 (2003).

[3] R. Osellame, S. Taccheo, M. Marangoni, R. Ramponi, P. Laporta, D. Polli, S. De Silvestri, and G. Cerullo, Femtosecond writing of active optical waveguides with astigmatically shaped beams, J. Opt. Soc. Am. B 20, 1559-1567 (2003).

[4] Y. Bellouard, A. Said, M. Dugan, and P. Bado, Monolithic integration in fused silica: When fluidics, mechanics and optics meet in a single substrate, in: International Symposium on Optomechatronic Technologies (2009) pp. 445-450.

[5] R. Osellame, G. Cerullo, and R. Ramponi, Femtosecond Laser Micromachining Photonic and Microfluidic Devices in Transparent Materials (Springer, Milano, 2012).

[6] R.R. Gattass and E. Mazur, Femtosecond laser micromachining in transparent materials, Nature Photon. 2, 219-225 (2008).

[7] R. Taylor, C. Hnatovsky, and E. Simova, Applications of femtosecond laser induced self-organized planar nanocracks inside fused silica glass, Laser Photon. Rev. 2, 26-46 (2008).

[8] K. Itoh, W. Watanabe, S. Nolte, and C.B. Schaffer, Ultrafast processes for bulk modification of transparent materials, MRS Bull. 31, 620 (2006).

[9] C. Hnatovsky, R.S. Taylor, E. Simova, P.P. Rayeev, D.M. Rayner, V.R. Bhardwaj, and P.B. Corkum, Fabrication of microchannels in glass using focused femtosecond laser radiation and selective chemical etching, Appl. Phys. Mater. Sci. Process. 84, 47-61 (2006).

[10]E. Glezer and E. Mazur, Ultrafast-laser driven micro-explosions in transparent materials, Appl. Phys. Lett. 71, 882-884 (1997).

[11]S. Juodkazis, K. Nishimura, S. Tanaka, H. Misawa, E.G. Gamaly, B. Luther-Davies, L. Hallo, 
P. Nicolai, and V.T. Tikhonchuk, Laser-induced microexplosion confined in the bulk of a sapphire crystal: evidence of multimegabar pressures, Phys. Rev. Lett. 96, 166101 (2006).

[12] A. Marcinkevičius, S. Juodkazis, M. Watanabe, M. Miwa, S. Matsuo, and H. Misawa, Femtosecond laser-assisted three-dimensional microfabrication in silica, Opt. Lett. 26, 277-279 (2001).

[13]Y. Bellouard, A. Said, M. Dugan, and P. Bado, Fabrication of high-aspect ratio, micro-fluidic channels and tunnels using femtosecond laser pulses and chemical etching, Opt. Express 12, 2120-2129 (2004).

[14] C. Hnatovsky, R.S. Taylor, E. Simova, V.R. Bhardwaj, D.M. Rayner, and P.B. Corkum, Polarization- selective etching in femtosecond laser-assisted microfluidic channel fabrication in fused silica, Opt. Lett. 30, 1867-1869 (2005).

[15] Sh. Rajesh and Y. Bellouard, Towards fast femtosecond laser micromachining of fused silica: The effect of deposited energy, Opt. Express 18, 2149021497 (2010).

[16] S. Kiyama, S. Matsuo, S. Hashimoto, and Y. Morihira, Examination of etching agent and etching mechanism on femtosecond laser microfabrication of channels inside vitreous silica substrates, J. Phys. Chem. C 113, 11560-11566 (2009).

\title{
STAČIAKAMPIŲ KANALU巳 FORMAVIMAS LAZERIU INICIJUOJANT CHEMINI ĖSDINIMĄ LYDYTAME KVARCE
}

\author{
V. Stankevič, G. Račiukaitis
}

Fiziniu ir technologijos mokslu centras, Vilnius, Lietuva

\begin{abstract}
Santrauka
Darbe pateikiami tyrimu rezultatai formuojant stačiakampio skerspjūvio kanalus tūriniame lydytame kvarce. Selektyvus cheminis èsdinimas kvarce buvo inicijuojamas apšvita femtosekundiniu lazeriu. Lazeriu modifikuotos bandinio sritys buvo lokaliai išèsdinamos fluoro rūgštimi. Pasiūlytas naujas metodas mikrokanalų
\end{abstract}

su norimu skerspjūviu formavimui, panaudojant daugkartini kanalo skenavimą. Buvo ištirta cheminio ésdinimo selektyvumo priklausomybé nuo lazerio spindulio skenavimo greičio, lazerio impulso energijos ir poliarizacijos, aptariami galimi modifikavimo procesai, sukeliantys nemonotonišką selektyvumo kitimą. 